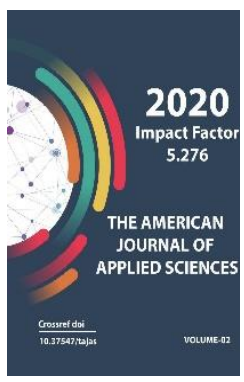

Copyright: Original content from this work may be used under the terms of the creative commons attributes 4.0 licence.

\section{The Analysis Of Influence Of Productions Of Open Mountain Works On Environment At Formation Of Various Zones On Deep Open-Cast Mines}

\author{
Nasirov Utkir Fatidinovich \\ Doctor Of Technical Sciences, Professor, Deputy Director Of The Almalyk Branch Of NUST \\ “MISiS", Almalyk City, Uzbekistan \\ Ochilov Shukhratulla Atoevich \\ PhD., Associate Professor, Department Of Mining, Tashkent City, 100095, Tashkent State \\ Technical University Named After Islam Karimov, Uzbekistan \\ Umirzoqov Azamat Abdurashidovich \\ PhD Scholar Of The Department Of Mining, Tashkent City, 100095, Tashkent State Technical \\ University Named After Islam Karimov, Uzbekistan
}

\title{
ABSTRACT
}

In the article ways of perfection of processes of chisel, explosive and excavation-loading works, moving of career cargoes, a sailing of formation and application of is cyclic-line technology on deep open-cast mines with is difficult-structural conditions for the purpose of reduction of an ecological damage by environment are considered. The analysis of studying of experience of development of mountain works on is difficult-structural deposits fulfilled in the open way where depth of mountain works reaches a point more than $500 \mathrm{~m}$ with division into the natural -technological zones is carried out.

\section{KEYWORDS}

Drilling and blasting, excavation and loading operations, dumping, cyclical-flow technology, production capacity, deep quarries, environmental damage, environment, rotary cone and pneumatic percussion drilling, steeply inclined conveyor.

\section{INTRODUCTION}

An analysis of the theory and practice of building deep quarries shows that with the improvement of technology and techniques of open pit mining, simultaneously with the improvement of technical and economic indicators of extraction, the impact of environmental damage on the environment decreases. This trend can be traced in almost all mining processes.An increase in the production capacity and depth of quarries 
leads to a concentrated technogenic impact on the environment, as a result of which the state of the human environment deteriorates. Such an impact consists of disturbance of the earth's surface as a result of mining and storage of industrial waste, geochemical contamination of land by dust and gas emissions from open pits, violation of the hydrogeological regime in areas adjacent to open pits, etc.

As you know, drilling operations are also progressing along the path of improving machine tools for roller cone and pneumatic percussion drilling with the suppression of dust by water and its capture using cyclone installations.Blasting operations are widely used to prepare rocks for excavation due to the manufacturability and the ability to quickly crush a significant volume of rock to the required degree. They are characterized by the following generalized indicators: useful work of explosion is less than $1-2 \%$ of the potential energy of the explosive charge; the loss of mineral resources as a result of a decrease in quality characteristics below economically and technologically acceptable conditions, in some cases, reach 70\%; during massive explosions to a height of 150-200 m, 40-50 thousand m3 of gases and 150-200 tons of dust are emitted, which are dispersed at a distance of about 15 $\mathrm{km}$.

At the same time, blasting operations are being improved by increasing the share of useful explosion work, reducing the loss of mineral raw materials and reducing dust and gas emissions in the following areas [1,2]: the introduction of cheap and safe emulsion explosives, the use of which allows you to regulate the energy of borehole charges and reduces gas emissions into the atmosphere quarries; blasting operations in a "squeezed" environment with a decrease in deformation of the rock mass during the explosion and gas emissions into the open pit atmosphere; blasting operations using a small amount of explosives, which significantly reduces the volume of a single dust and gas cloud, the height of its rise and the distance of propagation; the use of liquid-based stemming of borehole charges, which reduces dust and gas emissions and their spread over the adjacent territory; an increase in the height of the blasted benches, which makes it possible to significantly reduce the emissions of dust and gases into the open pit atmosphere while increasing the degree of useful use of the explosive charge energy you also need to focus on the use of the simplest home-made explosives, which are characterized by low cost, high level of safety and reduced environmental impact.

\section{MATERIALS AND METHODS}

In works $[3,4,5]$ it is noted that the improvement of excavation and loading operations is aimed, to one degree or another, at reducing the rigid dependence of the equipment parameters on the height of the bench being worked out and reducing the resources consumed during its operation. Firstly, this is achieved by creating milling machines that are able to mine rocks without preliminary loosening in any way, and secondly, by creating a continuous technique that can mine blasted rocks.

In the development of rocky massifs of rocks, the main excavation and loading unit is currently an excavator of the "mechanical shovel" type with a cable or hydraulic drive of the working body, as well as front-end bucket loaders. Moreover, in deep quarries with a dynamically developing working area, steep side slopes and a shortage of usable working space, preference is given to mobile excavation-loaders with autonomous power supply (front-end loaders, hydraulic excavators with an internal combustion engine, etc.).

When choosing the type of excavator, it should be borne in mind that with the same bucket capacity, the face height for a rope excavator is 1,3-1,4 times higher than for a hydraulic 
excavator. This is due to the design features of their working bodies and the linear dimensions of the excavator depend not only on the height of the ledge being developed and the performance of the equipment, but also on the level of selectivity in the development of the faces, which affects the loss and dilution of the mineral. The last argument is very important when developing complex-structured deposits. From the above, it follows that significant changes in technology and technique of excavation and loading operations in deep open pits are not expected, and one should focus mainly on traditional excavation and loading equipment - cyclic excavators "mechanical shovel" and front-end bucket loaders. In addition to drilling and blasting and excavation and loading operations, the processes of transporting rocks and dumping have a significant impact on the environment.

The main direction of improving the process of transporting rocks and minerals is to find technological solutions that reduce the distance of transportation and energy costs for its implementation. The most promising technology for deep quarries is the transition from cyclic technology to cyclic-flow. In this case, one should take into account: the choice of the design of conveyors, which affects the area of their application; conjugation of cyclic and flow links, which significantly affects the productivity of central heating complexes; minimization of the size of working platforms under the transfer points, which affects the size of temporary pillars; selection of the type of reloading point, which determines the complexity of its movement to a new place of work and the duration of the existence of a temporary pillar; the opening of new horizons, which determines the volume of mining and preparatory work. Other technical solutions are also possible to improve the process of transporting rock masses in deep quarries, for example, the use of ore and rock slopes in the CPT complexes.
At the same time, steeply inclined conveyors, as well as modular inter-ramp conveyors and crushing and transfer points, which can be easily moved from place to place and require a minimum of construction and mining preparatory work, can be considered a relatively new direction in the creation of equipment for CPT complexes for deep quarries.

The number of rocks in the dumps characterizes the level of use of mineral raw materials extracted from the subsoil during the extraction of a conditioned mineral.It is known that waste rock, substandard minerals are sent to the dumps, as well as part of the balance reserves, the quality characteristics of which are reduced as a result of clogging by rock and substandard raw materials during the development process. Since over time for each mining and processing enterprise there comes a moment when substandard minerals are involved in processing, dumps with such raw materials, being man-made deposits, become objects of mining.Consequently, such dumps should be formed taking into account their development in the future [6].

At the same time, the analysis of previous experience shows that the traditional ways of dumping cannot provide qualitatively new solutions that significantly reduce the distance of transportation and the size of the areas occupied by the dumps. The emergence of such solutions today is of significant importance also because the bulk of the rocks laid on the earth's surface are not intended to be used at all. Therefore, the dumps will have a negative impact on the environment for an indefinitely long time. From this point of view, the proposal to use the mined-out area of open pits for the placement of dumps, which is widely used in the development of stratal deposits, deserves the closest attention $[7,8,9]$. However, today it can be concluded that this technology has real prospects for implementation. For this, the conditions for 
the transition to internal dumping must be determined, and the worked-out space and the working area of the open pit must be prepared in advance for the placement of dumps with the adjustment, if necessary, of the mode and directions of mining operations.

An analysis of the study of the experience of the development of mining operations in complex-structured deposits mined by an open-cut method and where the depth of mining operations has reached a mark of more than $500 \mathrm{~m}$ shows that there is a division into zones at all open pits. For example, stripping and mining zones are almost always distinguished. In the Muruntau quarry, such a division was carried out according to the consumer properties of the rock mass, and the quarry was divided into ore, ore-rock and rock zones with different technologies for drilling, blasting, mining and loading, transport and storage operations. However, mining technical conditions changing as the depth of development inevitably sets in motion the mechanism for dividing the opencast into zones according to other criteria. For example, opening workings, the position of which has been chosen taking into account the rationalization of transport operations, can divide the open pit working space into zones in such a way that the mining mode will change significantly. Such a spontaneous division of the quarry into zones in some cases serves as a deterrent when mining in the given directions. Hence, it follows that the division of the quarry into zones should be purposeful, and their formation and development should be controlled. At the same time, the controllability of such a process presupposes the creation of a hierarchically organized system of natural and technological zones, in which the open pit is the upper, and the excavator face is the lower hierarchical level with characteristic dimensions, volumes of mining operations, tasks and management methods. Thus, the idea of such management is that the open pit workspace is divided into autonomously working natural-technological zones, interconnected by a common task, with a cyclical change in functional significance (role function),hierarchically organized internal division into mining blocks and control of the speed of mining operations by minimizing the parameters of mining blocks and maximizing the angles of inclination of the working sides. With all the variety of mining conditions and the specifics of mining operations in open pits, it is possible to identify common features according to which their working zone is divided into natural and technological zones. These signs include: - spatial position of the zone; - boundary elements of the zone; consumer properties of the rock mass; technology of work; - functional purpose (target function); - method of opening; parameters of cargo flows and their ability to combine with cargo flows of other quarry zones. The functional purpose of the naturaltechnological zone can be enhanced or weakened by the role assigned to this zone in solving the general problem of the open pit. It is this role that determines the priorities in the acquisition of the zone with loading and transport equipment, material and labor resources. Consequently, the naturaltechnological zones of the quarry should be ranked according to their importance. This prioritization not only greatly simplifies, but also greatly enhances the efficiency of mine management.

An analysis of mining operations in the Muruntau open-pit mine shows that, as it developed, the working area was divided into active and passive parts. At the same time, in the active part of the working zone, mining operations are being carried out, and in the inactive part, there is practically no mining work. The main limiting elements of the active part of the working zone are the North side of the open pit, set in the limit position for a long time, and the temporary pillar on the South side of the open pit with the opening trench and transport berms of the CPT complex 
located on it. As a result of such restrictions, mining operations are developing mainly in the direction of the western and eastern flanks, as well as in depth (Fig. 1).

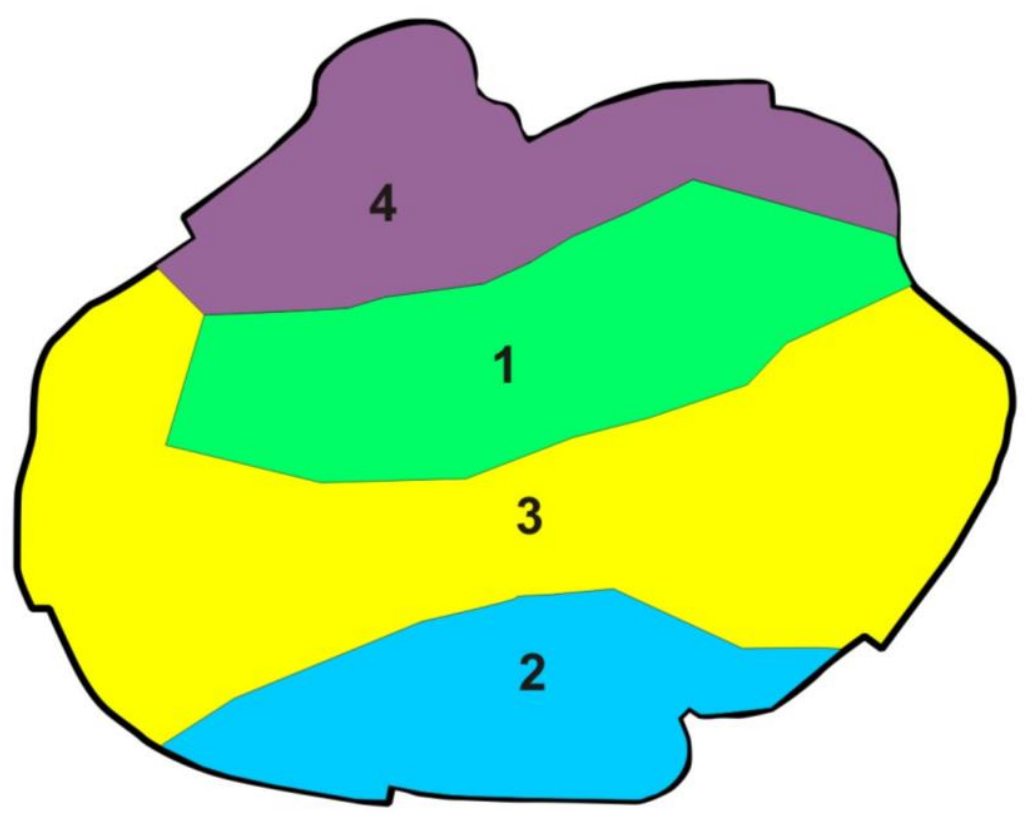

Figure: 1. Scheme of dividing the working area of the Muruntau open-pit mine into active and passive parts: 1 - non-working open-pit side; 2 - temporary rear sight;3 - the main working area; 4 - "North Board".

Further division of the open pit working area into natural and technological zones took place in accordance with the target function of each zone under the influence of the main opening workings located on the flanks of the temporary pillar and providing transport communication of the active part of the open pit working area with unloading points.As a result, in the process of purposeful formation of a pit opening scheme, the active part of the open pit working zone was additionally divided into natural-technological zones, each of which has its own target function (Fig. 2):

Zone 1. The northern wall (upper horizons) is a separate part of a quarry with an individual opening scheme and low-grade ore mass. The objective function is to replace the ore flow from the warehouses in the ore flow to the plant.

Zone 2. Western flank of the quarry. High quality ore mass is concentrated under the temporarily inoperative side. It is divided into two blocks: block 2.1 with the target function of stripping operations in the amount that ensures the specified ore production in block 2.2; block 2.2 with the target function of bringing the speed of mining operations down to $60-70 \mathrm{~m}$.

Zone 3. Temporary rear pillar. The objective function is the placement of excavation trenches and transport berms while minimizing the distance of transportation of the rock mass by road. 
Zone 4. Eastern flank of the quarry. The ore mass of good quality is concentrated under the temporarily inoperative side. It is divided into two parts: Block 4.1 with the target function of stripping operations to the extent that ensures the specified ore extraction in the natural technological block 4.2 ; block 4.2 with the target function of bringing the speed of mining operations down to $40-45 \mathrm{~m}$.

Zone 5. Pit bottom. High quality ore. The objective is to support mining operations in zones 1, 2 and 4, if necessary.
Zone 6. Southeast flank of the open pit. The objective is to provide preparation for the extraction of promising ore reserves.

Zone 7. North side of the quarry. The target function is to ensure the safety of mining operations at the lower levels of the open pit.

Zone 8. Northeast side of the open pit. The target function is to carry out mining and preparatory work to accommodate the steeply inclined conveyor of the CPT-ore complex.

Figure: 2.Scheme of dividing the working area of the open pit into natural-technological zones:

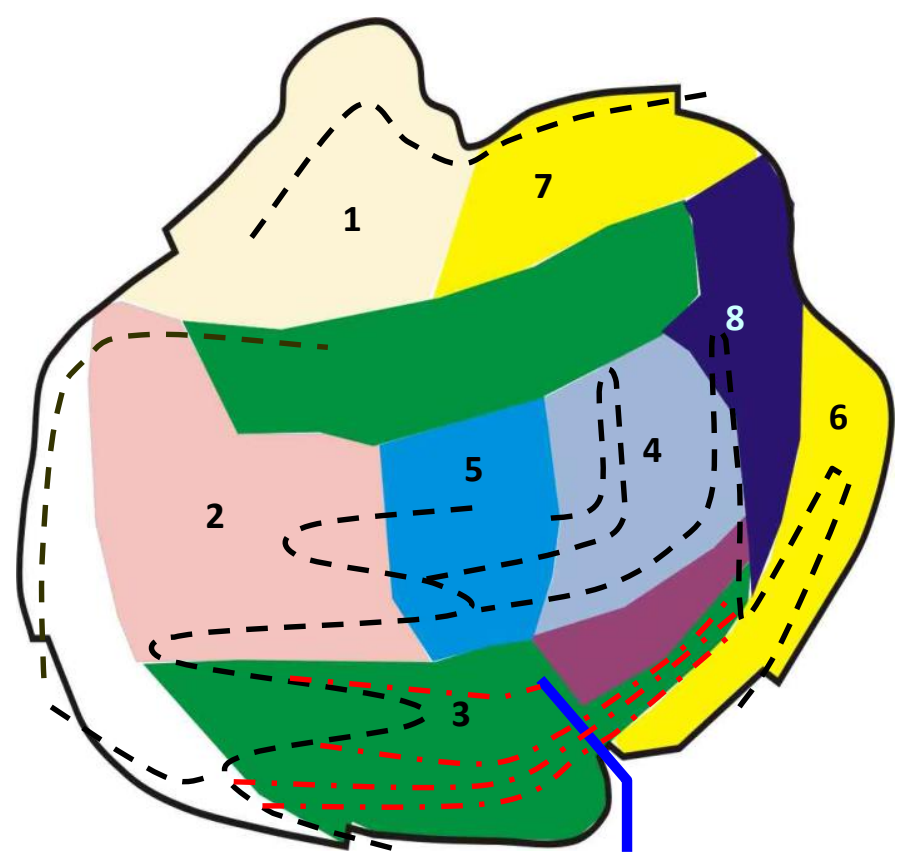

car trenches;

concentrationhorizons;

CPT conveyors 
The ranking of natural and technological zones in terms of importance is assessed by the contribution of each zone to solving the main problem of the open pit. At the same time, it was found that zones 2 and 4 (West and East) are of the greatest importance for mining, due to which at least $90 \%$ of the production of commercialore is provided. At the same time, there is an increase in the role of Zone 1 (North Board) in the supply of raw ore and Zone 6, which practically does not affect mining operations in the next 4-5 years, but ensures timely preparation of reserves in the lower horizons of the open pit. It should be borne in mind that the priority of the naturaltechnological zone changes over time, and such changes imply the adjustment of plans.

Analysis of the mining situation in a quarry shows that such separating features as the consumer properties of the rock mass and the work technology take place in naturaltechnological zones with different functional purposes. This situation predetermines the consolidation of cargo flows and the need for coordinated development of natural and technological zones, which should be implemented in the management of mining operations.

\section{CONCLUSION}

Thus, when conducting open pit mining, excess pollution of the atmosphere of deep open pits is inevitable. And since the use of artificial ventilation in this case is unpromising, then the most realistic way to protect a person from the effects of harmful impurities is to equip the cabins of mining equipment with filtering installations that clean the air from aerosols and gases. In general, the analysis of the actual situation that has developed to date in the development of solid mineral deposits allows us to note the following emerging main trends in the development of deep quarries:

- The known methods of blasting and crushing the rock mass are insufficient to minimize the unproductive losses of the explosion energy, allowing to reduce the cost of blasting and to increase the productivity of mining equipment;

- A decrease with the depth of mining of natural fracturing and an increase in the proportion of strong rocks, which leads to an increase in the energy intensity of drilling and blasting crushing;

- Expansion of the scope of application of cyclical-flow technology of mining operations, do not fully meet the efficiency of deep open pits;

- The known methods of designing open pits do not fully meet the specified criteria and restrictions for substantiating the methods of rational development of small-scale and man-made gold deposits;

- The existing systems for managing the mineral resource base of the gas processing complex during the development of deposits of natural and man-made origin do not fully increase the efficiency of mining operations.

\section{REFERENCES}

1. Sytenkov V.N., Shemetov P.A. Muruntau is in the middle of the road. // Metals of Eurasia. - 2002, No. 2. P.20-22.

2. Shemetov P.A., OchilovSh.A. Improvement and development of blasting operations in Uzbekistan // Mining Bulletin of Uzbekistan, No. 4, 2013. P.14-18.

3. Rubtsov S.K., Shlykov A.G., Shemetov P.A. Improving the efficiency of drilling and blasting operations in the open pits of the combine // GornyiZhurnal. - 1998, No. 8. P. 41-45.

4. Nasirov U.F., Ochilov Sh.A.,UmirzoqovA.A.Analysis of Development of Low-Power and ManMade Gold Deposits//International Journal of Academic and Applied Research (IJAAR)ISSN: 2643-9603 Vol.4,Issue 4,April-2020,P: 71-74. 
5. Umirzoqov A.A., Jurayev S.J., Karamanov A.N. Economic and mathematical modeling of rational development of small-scale and man-made gold deposits// International Journal of Academic and Applied Research (IJAAR), Vol. 4, Issue 4, April - 2020, Pages: 75-77.

6. HayitovO.G.,UmirzoqovA.A.,Iskandarov J.R., Suvanov F.R. Prospects for the industrial use of coal in the world and its process of reproducing//Novateur Publication's JOURNALNX- A Multidisciplinary Peer Reviewed Journal, Volume 6, Issue 5, may-2020, Pages:240247.

7. Kazakov A.N., Umirzoqov A.A., Radjabov Sh.K., Miltiqov Z.D. Assessment of the Stress-Strain State of a Mountain Range// International Journal of Academic and Applied Research (IJAAR), Vol. 4 - Issue 6 (June - 2020), Pages:17-21.

8. Nasirov U.F., Ochilov Sh.A., Umirzoqov A.A. Theoretical Calculation of the Optimal Distance between Parallel-close Charges in the Explosion of High Ledges// Journal of Advanced Research in Dynamical and Control Systems - JARDCS, Vol. 12,07special issue, 2020, Pages: 2251-2257.

9. Umirzoqov A.A.,Karamanov A. N., Radjabov Sh. K. Study of the feasibility of using intermediate buffer temporary warehouses inside the working area of the Muruntau quarry// International Journal of Engineering and Information Systems (IJEAIS), Vol. 4, Issue 8, August - 2020, Pages 140-142.

10. Khayitov O.G', Umirzoqov A.A.,Bekmuratov A.O. Small Torch Progress In Prospects Gold Mining In Improving Countries// The American Journal of Interdisciplinary Innovations and Research, 2(09), 65-72.

11. Mirzarakhimov M.S., Iskandarov J.R.,Umirzoqov A.A.,Amanov T.S. Technology Of Modified SodiumAluminum Catalysts For Nitrogen Gas
Purification Systems// The American Journal of Applied Sciences, 2(09),154-163.

12. Khakimov K.D., Eshonqulov U.K., Amanov T.S., Umirzoqov A.A. Complex Processing Of Lead-Containing Technogenic Waste From Mining And Metallurgical Industries In The Urals// The American Journal of Engineering and Technology, 2(09), 102108.

https://doi.org/10.37547/tajet/Volumeo2ls sueog-19

13. Sytenkov V.N. Management of the dust and gas regime in deep quarries. - $\quad M$. OOO "Geoinformcenter", 2003. - 288 p.

14. Nasirov U.F., Ochilov Sh.A. Analysis of the impact of drilling and blasting and excavation and loading operations on the environment // Proceedings of the XIV International Conference "Resourceproducing, low-waste and environmental technologies of subsoil development", Russia-Kyrgyzstan, 2015, p 273-275.

15. G'ofurovich, K. O., Abdurashidovich, U. A., Ugli, M. U. F., \& Ugli, A. A. X. (2020). Justification of The Need For Selective Development of The Phosphorite Reservoir By Horizontal Milling Combines. The American Journal of Engineering and Technology, 2(11), 159-165.

16. G'ofurovich, K. O., \& Abdurashidovich, U. A. (2020). Justification of rational parameters of transshipment points from automobile conveyor to railway transport.

17. Abdurashidovich, U. A. (2020). The Condition Of General Development Of The Mineral Resource Base In Uzbekistan. The American Journal of Applied Sciences, 2(12), 1-6. https://doi.org/10.37547/tajas/Volumeo2ls sue12-01

18. Ochilov, S. A., \& Nasirov, U. F. (2017). The oretical study of the fracture mechanism of less fissured rocks. Austrian Journal of Technical and Natural Sciences, (1-2), 98101.

19. Nasirov, U. F. Ochilov Sh. A., Umirzoqov AA Theoretical Calculation of the Optimal 
Distance between Parallel-close Charges in the Explosion of High Ledges. Journal of Advanced Research in Dynamical and Control Systems-JARDCS, 12, 2251-2257.

20. Prokhorenko G.A., Sytenkov V.N., Shemetov P.A. GPS is a system for dispatching control of the excavator and truck complex and the quality of ore flow in deep open pits. // Mining inform.- analyte. newsletter. MGGU.-2001, No. 11P. $65-69$

21. Shemetov P.A., Nasirov U.F., OchilovSh.A. Rationalization of the technological scheme for the development of mining in the open pit "Muruntau" // Mining information and analytical bulletin, No. 8, 2014. Ed. MGGU (Moscow). P.82-87. 